\title{
Automated mineralogy and petrology - applications of TESCAN Integrated Mineral Analyzer (TIMA)
}

\author{
Tomáš HRSTKA ${ }^{1 *}$, Paul GOTTLIEB² ${ }^{2}$ Roman SKÁLA', Karel BREITER¹, David MOTL³ \\ ${ }^{1}$ Institute of Geology, The Czech Academy of Sciences, v.vi., Rozvojová 269, 16500 Prague 6-Lysolaje, Czech Republic; hrstka@gli.cas.cz \\ 2 TESCAN ORSAY HOLDING, a.s., Libušina třida 21, 62300 Brno, Czech Republic \\ ${ }^{3}$ TESCAN Brno, s.r.o., Libušina třída 1, 62300 Brno, Czech Republic \\ * Corresponding author
}

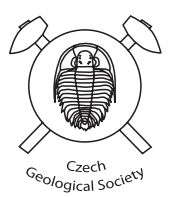

\begin{abstract}
The collection of representative modal mineralogy data as well as textural and chemical information on statistically significant samples is becoming essential in many areas of Earth and material sciences. Automated Scanning Electron Microscopy (ASEM) systems provide an ideal solution for such tasks. This paper presents the methods and techniques used in the recently developed TESCAN Integrated Mineral Analyzer (TIMA-X) with Version 1.5 TIMA software. The benefits from the use of a fully integrated quantitative energy-dispersive X-ray spectrometry (EDS) and an advanced statistical approach to ASEM systems are demonstrated. Typically, the system can handle more than 500,000 X-ray events per second. Using a common spectral total of 1000 events this represents the acquisition of 500 spectra per second. A number of measurement modes is available to make the most effective use of these spectra depending on the application. For a back-scattered electrons (BSE) map combined with EDS data with spatial resolution of $10 \mu \mathrm{m}$, this represents the high-resolution measurement of $c .1 \mathrm{~cm}^{2}$ of a thin section or a polished rock surface in 30 minutes. A patented X-ray spectrum clustering algorithm that lowers the chemical detection limit is described and an example of its use is shown. The modal and textural (liberation, association, size etc.) data produced are statistically robust and provide information across a broad range of Earth and material sciences. A comparison with some other available instruments is also provided together with a number of case studies.
\end{abstract}

Keywords: TIMA, Automated SEM/EDS, applied mineralogy, modal analysis, artificial intelligence, neural networks

Received: 9 October 2017; accepted: 6 March 2018; handling editor: F. Laufek

The online version of this article (doi: 10.3190/jgeosci.250) contains supplementary electronic material.

\section{Introduction}

Information on the modal composition of samples (i.e. volume $\%$ or weight $\%$ of minerals/phases present) and understanding of their textural relationships are essential in petrologic and petrogenetic studied (Le Bas and Streckeisen 1991; Le Maitre 2002), modelling of ore formation (Rollinson et al. 2011; Smythe et al. 2013; Nie and Peng 2014; Santoro et al. 2014) and in fact in any research related to Earth or material sciences (Gottlieb 2008; Pirrie and Rollinson 2011). Optical microscopy, powder X-ray diffraction (PXRD), scanning electron microscopy (SEM), often supplemented with energydispersive X-ray spectroscopy (EDS) and electron-probe microanalysis (EPMA) have represented the key methods used to characterize material properties in the past. Although these techniques still play a crucial role in mineralogy, petrology and geology, the last two decades have seen the widespread use of SEM-based Automated Mineralogy (AM) systems to help identifying minerals by their composition and to quantify their proportions, size and textural relations (Hoal et al. 2009; Pérez-Barnuevo et al. 2013). By contrast, automated optical microscopy instruments are still rather rare and have a limited use because of the difficulties involved in automatically identifying minerals by their color and other properties in reflected light and polarized transmitted light (Pirard 2004; Donskoi et al. 2007; Lane et al. 2008; Poliakov and Donskoi 2014; Berrezueta et al. 2016).

Automated Mineralogy instruments such as QEMSCAN (Gottlieb et al. 2000) and MLA (Fandrich et al. 2007) were initially designed mainly for use in mineral processing to determine particle mineral liberation from representative samples of plant products (i.e. feeds, concentrates and tailings). These systems are indeed useful for plant optimization and feed ore characterization for predicting concentrator and leaching performance from ore properties such as grade, elemental deportment, locking, grind size, hardness, and reagent consumption.

Lately, the AM systems have also progressively found their way into many geological research laboratories where they are now being widely used for gathering mineralogical and petrological data. They have been employed to visualize and quantify petrological properties such as alteration, contact zones, fractures, exsolution structures, deformation re-crystallization and mapping 
distribution of inclusions as well as other data (Andersen et al. 2009; Haberlah et al. 2010; Knappett et al. 2011; Rollinson et al. 2011; Santoro et al. 2015; Ackerman et al. 2017; Ward et al. 2018).

The AM systems have a number of time- and statisticsoptimized analysis methods and modes of operation specifically customized for various industrial and research tasks. These include particle scans, field scans, line scans, specific mineral search routines and other more complex modes (Gottlieb et al. 2000; Fandrich et al. 2007). All these AM systems are based on acquisition, presentation and analysis of hyperspectral data (usually created by a combination of BSE and elemental maps) representing a 2-dimensional (2D) image of flat mineral/phase sections typically for large, statistically significant areas of the sample. A recent trend is that manufacturers of more classic SEM/EDS hardware and elemental quantification software are also starting to follow the example set by AM systems away from traditional (point analysis) and "elemental mapping" to more useful "phase mapping". Their goal is to create 2D mineral/phase images from geological and other specimens though typically on a smaller scale due to the time constrains (Johnson et al. 2015). It might be foreseen that the two approaches will possibly slowly converge while at the moment combinations of both concepts might be necessary to provide the right answers.

In this article we summarize some basic concepts of the use of AM systems in geosciences. Moreover, we demonstrate the latest developments of the TESCAN Integrated Mineral Analyzer (TIMA-X) system and its applications on several typical examples. Some suggestions are also made for further developments towards universal, statistically sound instrumental methods for the analysis of minerals and rocks.

\section{TESCAN Integrated Mineral Analyzer (TIMA)}

\subsection{TIMA hardware}

The TIMA-X system is based on one to four Energy Dispersive X-ray silicon drift detectors (SDD) attached to standard LM (small) or GM (large) chambers of the TESCAN MIRA (field-emission gun - FEG) or VEGA (thermionic emission - tungsten) platforms.

High throughput is achieved by the use of multiple TIMA EDS detectors operated at very high count rates (in excess of 2,000,000 counts per second, as measured on a platinum standard) and using low-count EDX spectra to identify the minerals at each measurement point (or each homogeneous segment/part of a grain depending on the analysis mode). Hardware and software integration is also very important. In contrast to classical EDX phase mapping software that requires high count numbers to be collected at each map pixel, the TIMA system is optimized to deal with rapidly acquired low-count spectra.

The TIMA has specific capabilities for geological applications because of its specialized integration of hardware and software and its high level of automation. The speed, automation and unattended operation allow the researcher to collect detailed data that were not possible to obtain through human-interactive operation of an SEM/EDX system. The multiple EDX detectors, in addition to providing a speed multiplier, have a side-benefit of reducing shading for artefact-free measurement of uneven surfaces with an imperfect polish.

Apart from the back-scattered electron (BSE), secondary electron (SE), and EDS detectors, the TIMA system can be also accompanied by cathodoluminescence (CL) detector for simultaneous acquisition of CL data during the measurements. An integrated Raman spectroscopy system is also available as an option.

For the larger chamber, up to nine $27 \times 47 \mathrm{~mm}$ thin sections or fifteen $30 \mathrm{~mm}$ diameter or twenty two $25 \mathrm{~mm}$ diameter polished blocks can be analyzed in a single batch. The smaller chamber accommodates two $27 \times 47$ $\mathrm{mm}$ thin sections or seven $30 \mathrm{~mm}$ diameter or $25 \mathrm{~mm}$ diameter polished blocks. A fully automated system ("autoloader") that is capable of sample exchanges for one hundred $30 \mathrm{~mm}$ diameter or $25 \mathrm{~mm}$ diameter polished blocks is also available.

All the processing of spectral phase classification is performed already during the data collection in order to use the time efficiently and to produce results by the time when the acquisition is finished. The raw data are also saved together with the processed results to allow for modification of the parameters and off-line reclassification and/or reinterpretation of the measurements.

\subsection{Back-scattered electron (BSE) image analysis}

Imaging and image analysis are fundamental to automated mineral analysis. A stable and well calibrated BSE image is a prerequisite for its proper implementation (Fandrich et al. 2007). The machine calibration is performed on a Faraday cup and a platinum standard; automated checks and optimizations for long-term measurements are included in the system. At the typical working conditions, the stability of the probe current is better than $0.5 \%$ in 24 hours (for both tungsten and field-emission systems). Consequently, the BSE signal, which depends on the probe current, displays the same $(0.5 \%)$ level of stability. It means that if a typical mineral has a mean BSE level of 50.00 arbitrary units, it will not change more than \pm 0.25 in 24 hours. The probe current and BSE detector parameters are adjusted 


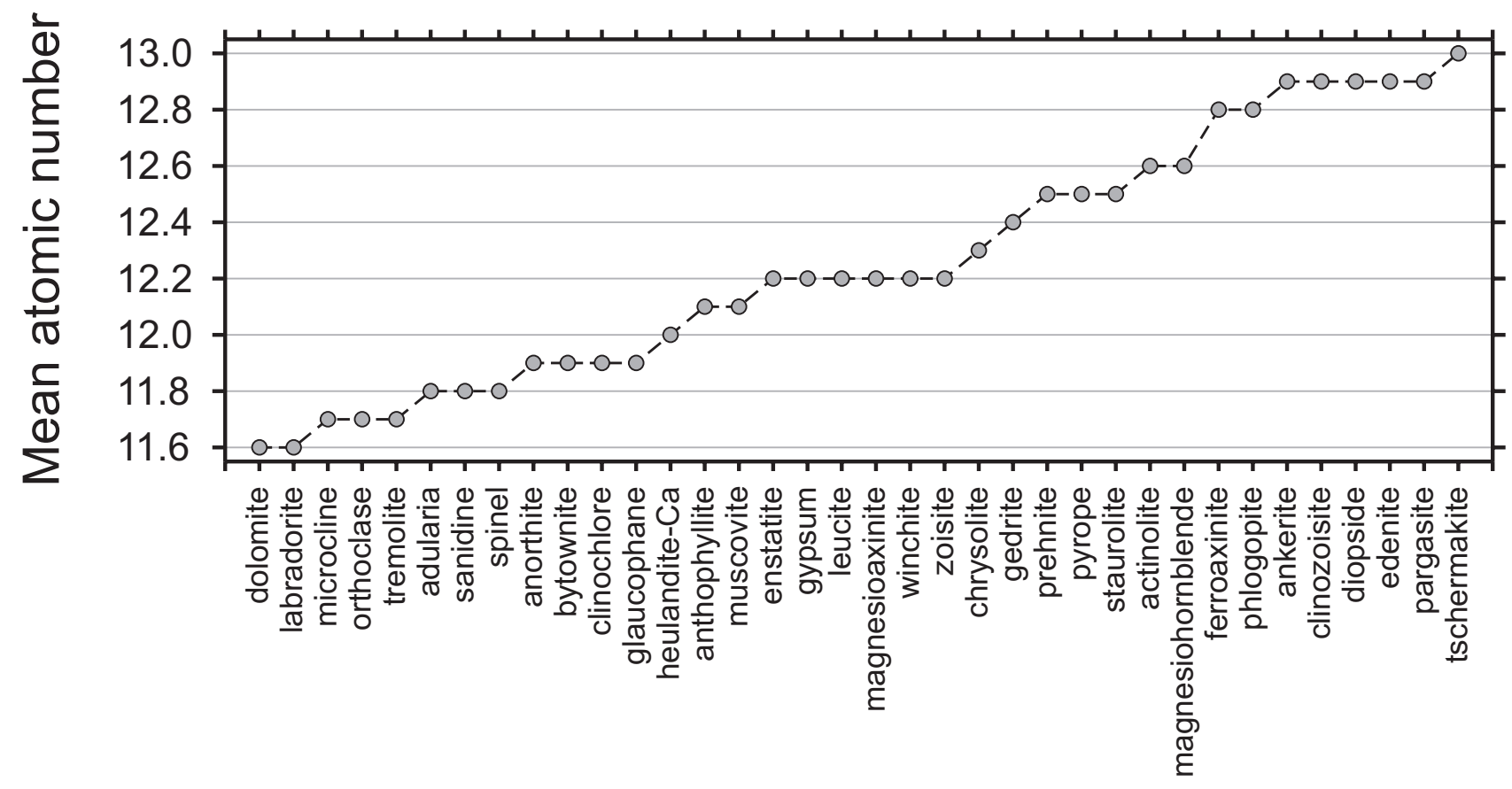

Fig. 1 Mean atomic number (Z) plotted for selected minerals and phases to demonstrate the BSE overlaps.

automatically to maintain optimum stability. This also allows for easy discrimination of phases on a long-term run with BSE image only.

Due to a number of factors the BSE calibration curve of individual BSE detectors is not linear, which creates potential problems in cross-correlation with other systems. Therefore the use of the average atomic number $(\mathrm{Z})$ to monitor the BSE response of a mineral/phase could be suggested to overcome this calibration problem. Lloyd (1987) has examined in detail the use of BSE signal in mineralogy.

It should be noted that the short-term stability and resolution are generally much higher than the long-term one ( $\sim 0.1 \mathrm{Z}$ compared to $\sim 1 \mathrm{Z}$ or more). This leads to the important ability to use the relative BSE brightness for image/phase segmentation, but gives it a more limited use in the actual mineral/phase identification.

There have been attempts to use the BSE-only approach (Harding 2002; Sánchez et al. 2012) but its application to more complex tasks is rather limited due to the common overlaps of BSE values of individual minerals and their high variability even within a single mineral species (Fig. 1). Among the $\sim 6,000$ known minerals and valid unnamed minerals (Smith and Nickel 2008), there are over 700 cases of overlapping BSE image data because of differences in average atomic numbers being below $0.1 \mathrm{Z}$. This does not even take into account variations based on difference in BSE within a single mineral species due to elemental substitutions. Therefore the use of combined BSE and EDS is strongly advisable.

\subsubsection{Particle de-agglomeration}

For particulate samples such as mineral sand, dust, soils or milled products the TIMA system has an automated touching-particle function that detects agglomerates (Hrstka 2008; Kwitko-Ribeiro 2012). The TIMA separates particles according to a set of predetermined parameters. This functionality is crucial if textural characteristics of individual particles/grains are of interest to prevent false association or size-distribution data.

\subsection{Phase segmentation}

Once individual segments have been identified by the initial BSE image, the next step of the mineralogical analysis is to delineate coherent segments of BSE and EDS spatial data by the clustering/edge detection method (Motl and Filip 2013). The segmentation is an important step that enables the creation of high-count spectra suitable for EDS quantitative analysis. This unique approach provides a means by which to assign the directly measured chemistry to each of the measured phases as needed. The individual low-count spectra typically used in AM systems ( $\sim 1000$ to below $\sim 20,000$ counts $)$ are not suitable for generating precise and accurate quantitative elemental information.

The segmentation is done after data acquisition, by creating a gradient image using the BSE image and the elemental X-ray intensities. The gradient image is then processed by a watershed transformation that detects continuous edges. The watershed transformation uses 


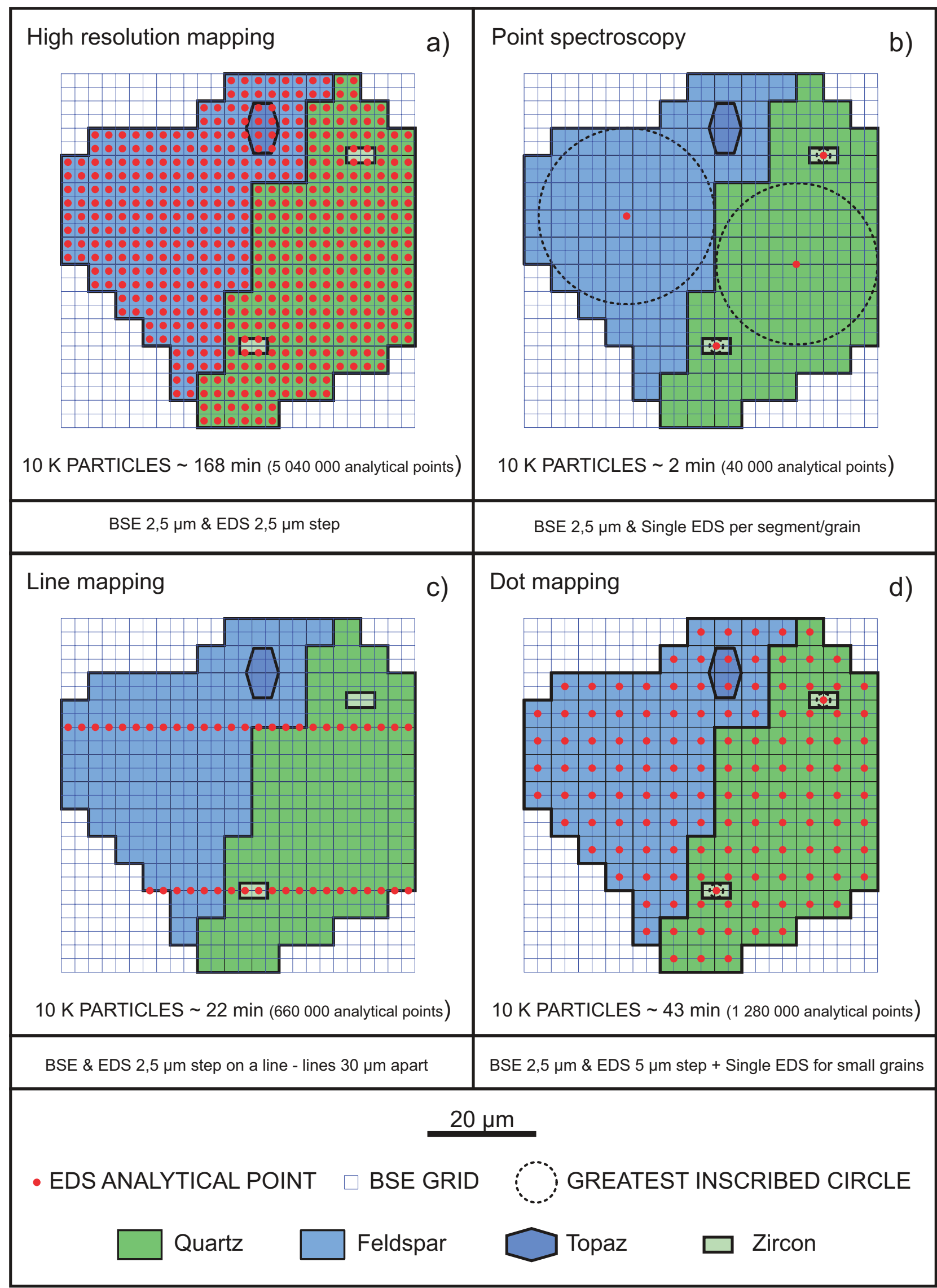


one parameter - the minimum gradient that is regarded as an edge. The value of this parameter is controlled by the user. Whenever two segments in contact have a similar composition and, as a result, the gradient between them is low, they are merged into a single segment rather than remain separated. The minimum gradient parameter is used to increase the separation of such phases. If it is too high, the software creates too many segments and, as a result, this yields large datasets and off-line reclassification and data processing takes more time.

\subsection{Mineral identification by BSE and X-ray analysis (Acquisition Modes)}

The TIMA currently has four X-ray analysis scanning modes to identify mineral species: High-resolution mapping, Point spectrometry, Line mapping and Dot mapping. These modes have been developed to economize on the X-ray acquisition time. Each mode can be further optimized to perform specific tasks. The most important optimization parameters are the number of $\mathrm{X}$-ray counts per analytical spectrum and the distance spread (pixel spacing) of individual analytical points (Fig. 2).

\subsubsection{TIMA High-resolution Mapping (THRM)}

In this mode the TIMA first collects the BSE signal at the analytical point and then one X-ray spectrum (typically $>1000$ counts) for each point over a regular grid within each segmented particle. The BSE level is used as a threshold so that if the BSE level is outside the specified range (e.g. epoxy), the X-ray spectra are not collected in order to save run time (Fig. 2a). This method can be used to handle various rocks with complex textures or other samples where detailed resolution is required. Due to the optimized data processing and simultaneous use of four SDD detectors, the TIMA acquisition rate, when translated into measurement time elapsed, is approximately 30 minutes for the analysis of $1 \mathrm{~cm}^{2}$ of a granitic rock at $10 \mu \mathrm{m}$ pixel spacing and 1000 counts per spectrum per point (in the THRM mode). This acquisition mode, together with the liberation analysis, can be used to collect modal and textural data (e.g., Žák et al. 2016).

Fig. 2 Sketch illustrating the principles of TIMA acquisition modes. a - High-resolution mapping using the same regular BSE and EDS analysis grid. $\mathbf{b}$ - Point mapping uses BSE only to segment the image and collect single EDS spectra from each phase discriminated based on BSE. $\mathbf{c}$ - Line mapping records one-dimensional profiles through the sample. d - Dot mapping uses different pixel spacing for the BSE and EDS data collection.

\subsubsection{TIMA Point Spectrometry (TPS)}

In point spectrometry, individual particles and distinct phases/grains are determined using the BSE image only. Areas of similar BSE brightness are identified as homogeneous regions. The center of the largest inscribed circle of each region is then used as a single $\mathrm{X}$-ray analysis point to identify a mineral or a phase representing the entire region (Fig. 2b). This method is very fast, but cannot resolve two adjacent phases with similar mean atomic numbers but different chemistry and thus can lead to large areas of misclassification (Fandrich et al. 2007). It can be used to handle various geological samples as far as the minerals of interest have sufficient BSE grey level contrast. This can be difficult to predict for unknown samples and thus only well-known/previously studied samples can be recommended for this type of analysis. Its definite advantage is the high speed as only a single spectrum is collected per homogeneous BSE segment. As stated previously, $\mathrm{Z}$ resolution is highly dependent on measurement parameters like beam current, brightness/ contrast settings of the instrument, quality of the sample surface, focus etc. (Lloyd 1987; Harding 2002).

\subsubsection{TIMA Line Mapping (TLM)}

Line mapping is used to reduce $\mathrm{X}$-ray acquisition time but still maintain some textural information such as mineral grain size and mineral association. For line mapping each field is covered by equidistant horizontal lines using a specified "line spacing" (Fig. 2c). The electron beam moves along each line in regularly distributed measurement points using the specified "pixels spacing". At each point, the BSE level is determined, if the BSE level is above the threshold, the beam is kept on this spot until the specific number of X-ray counts from the spectrometer is collected. The beam then moves to the next point. When the pre-determined limit of the line length (field size) is reached, the beam moves to the next line and starts over. This procedure is repeated until all lines covering the selected field have been scanned.

Then, the individual lines are divided into multiple linear sections using the combination of the BSE level and the EDS data to determine boundaries between distinct phases.

The EDS data from the measurement points within each line section/segment are summed. The mean BSE level for each line section/segment is determined as well. The mean BSE level and the combined spectrum are used to classify the line sections using the specified classification scheme to determine the mineral/phase.

The advantage of this method in comparison with Point Spectrometry method is that it resolves boundaries between phases with similar mean atomic number but 


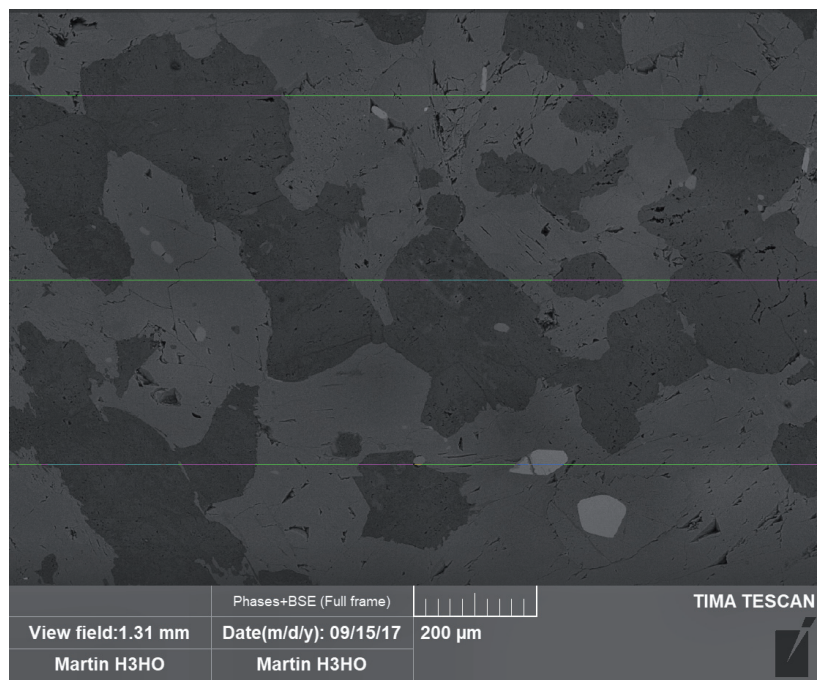

Fig. 3 Example of thin section modal analysis by the means of TIMA Line Mapping (TLM). Quantitative modal data are obtained fast (10 min for the whole thin section) while textural context is provided by the simultaneously acquired BSE image. different chemistry, and still provides high speed. This method gives only bulk association and modal data due to one dimensional cuts through the particles rather than two dimensional maps of each particle. However, it has the advantage of enabling the measurement of more particles to obtain better sampling statistics.

It can be used to handle various complex geological samples with the advantage of high speed if the collection of the full set of quantitative textural data is not critical. It also stores BSE images of each field so the operator can assess the quality of the results (perform QA, i.e. quality assurance) easily and get detailed qualitative information on textures from the BSE images (Fig. 3).

\subsubsection{TIMA Dot Mapping (TDM)}

Dot mapping imposes a BSE grid with specific resolution (determined as "pixel spacing") over the entire sample, or specific particles/grains thereof (based on the BSE threshold). It uses the acquired image to segment areas of homogeneous BSE intensities and identifies the center

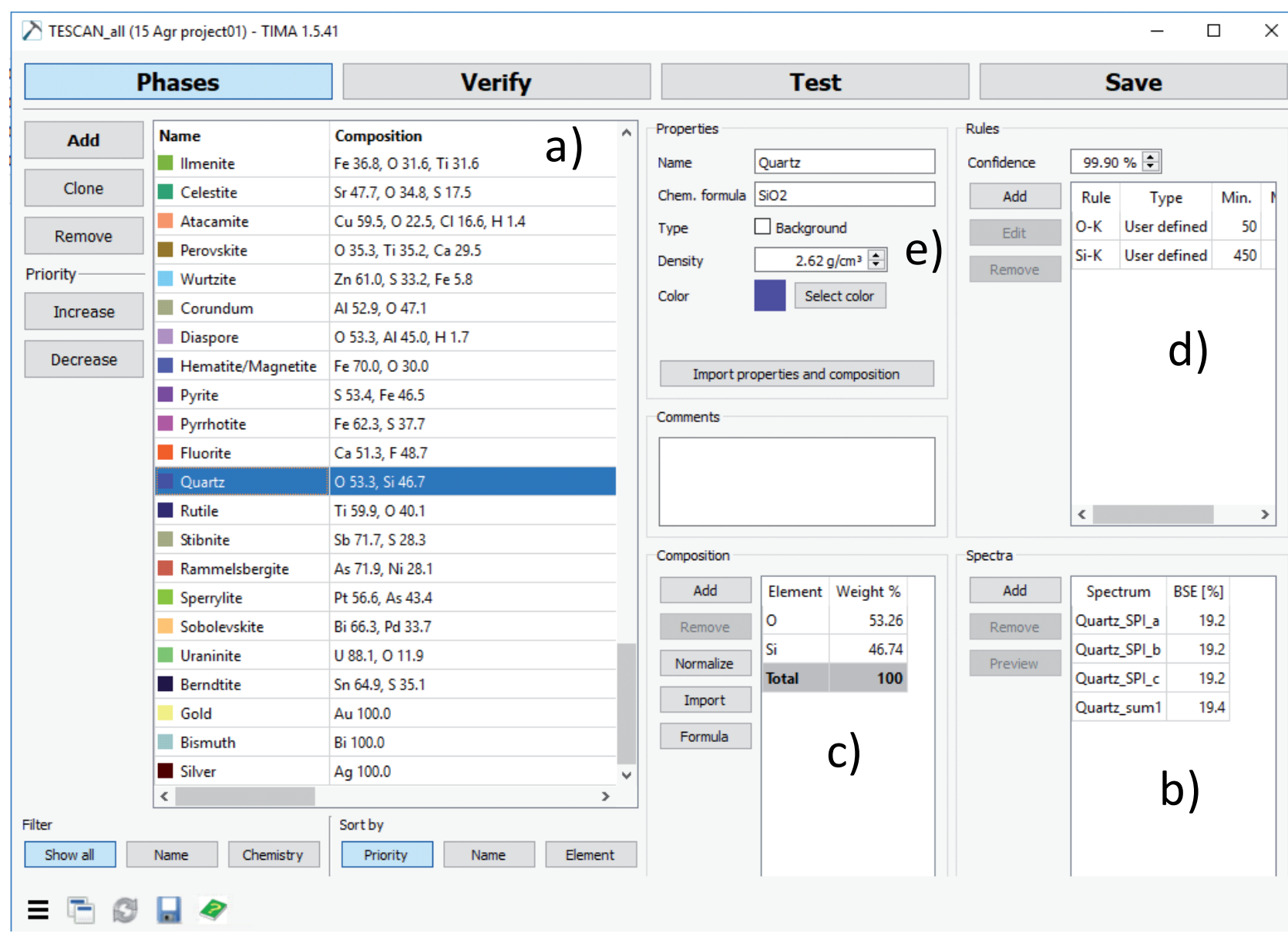

Fig. 4 Examples of a basic classification scheme with classification rules and mineral data for quartz selected. a - Database/list of minerals in a basic classification scheme. $\mathbf{b}$ - Standard spectra taken from the measured sample or calculated from stoichiometry/theoretical values. $\mathbf{c}-\mathrm{Chemical}$ data acquired from the EDS during the measurement or imported from an external source. $\mathbf{d}$-Classification rules automatically generated based on the standard spectra (b). $\mathbf{e}-$ Mineral properties like name and density assigned to the selected mineral entry. 
of greatest inscribed circle. In the second pass it creates a rectangular grid for X-ray acquisition with resolution specified by the "dot spacing" over each of the "preliminary" BSE phase segments determined in the first step. The combination of the high-resolution BSE image and the lowerresolution EDS data is used to greatly improve the phase segmentation when the preliminary segments comprise of multiple minerals/phases with similar $\mathrm{Z}$ but different chemistry. X-ray data from zones of similar BSE and EDS signals are summed to produce single higher quality spectra for each final segment. Average BSE and summed spectra from each final segment are used to determine the mineral identity. The origin of the second X-ray data grid is centered on each segment. This means that even grains smaller than the "dot spacing" of the X-ray data grid are characterized by at least a single X-ray analysis point.

The Dot Mapping method provides an excellent compromise between the high-resolution mapping and the point spectrometry method in terms of speed versus textural/information detail. As a single X-ray spectrum is collected even for particles smaller than the "dot spacing", even the smallest bright particles and textures are recorded (Fig. 2d).

The data collection procedure can be customized for specific tasks by the variation of its parameters (e.g. very fast analysis of a thin section - Slavík et al. 2016; Ackerman et al. 2017) or very detailed, submicron analysis of complex dust particles or soil contaminants (Harvey et al. 2017; Hrstka et al. 2017a, b).

\subsection{Mineral standards library (Classification Scheme)}

Mineral identification through BSE signals, EDS data or the combination of both requires a library of mineral compositional limits/mineral definition rules or standard spectra (Classification scheme in TIMA - Fig. 4). Any unknown spectra collected from a point or a segment, together with related information from other detectors (BSE, CL, SE etc.), are used to find the closest or first match to the records in the database providing mineral/ phase identification. For TIMA, a first match principle is used being based on the combination of mineral definition rules, either determined automatically (from a "standard spectrum" or calculated from a theoretical mineral/phase composition) by the system or created by the user from BSE, X-ray spectral windows counts and/or their ratios. The automation in creating the rules based on standard spectra significantly reduces the time spent on building a classification scheme, especially when tens or hundreds of potential phases are involved. A classification scheme provides not only the name of the identified phase, but also information on its exact chemistry and density needed in all subsequent modal or elemental deportment calcula- tions. The phase chemistry for a specific classification scheme can be based directly on the collected EDS data, taken from the theoretical stoichiometric composition, or entered manually based on a relevant external analysis [e.g. EMPA, Laser-Ablation Inductively Coupled Plasma Mass Spectrometry (LA-ICP-MS), Proton-Induced X-ray Emission (PIXE), or Micro X-ray fluorescence ( $\mu \mathrm{XRF})]$. These external analyses can account for elements which are sometimes present in phases in trace amounts but are important for the overall element distribution of the sample (e.g. gold in pyrite, nickel in goethite). This is particularly important for phases containing elements with concentrations below EDS detection limits.

The density as a first approximation is based on the mineral/phase identity or external study of the mineral/ phase. There is no direct means currently available for measuring mineral density inside a SEM.

Built-in QA routines provide a confusion matrix to point the user to potential problematic phases which could be misidentified $/ \mathrm{mismatched}$ due to overlaps in the classification parameters. Basic classification schemes are provided with the system as a starter kit. The Webmineral database (Mineralogical database 2017) is included to allow for quick and easy creation of classification scheme entries from theoretical mineral formulae matching the specific project needs.

In order to further simplify the current workflow, a supervised or fully autonomous system based on artificial intelligence, machine learning and neural networks is under development (Hrstka et al. 2017a).

\subsection{Measurement analysis types}

The TIMA software uses several acquisition modes (Section 2.4 above) to create various Measurement Analysis Types designed to accommodate different mineralogical and petrological information requirements. The Measurement Analysis Types and their associated Acquisition Modes are summarized in Tab. 1 and described below.

\subsubsection{TIMA Modal Analysis (TMA)}

This is the most basic analysis method in which only the modal data are collected through "high-resolution map-

Tab. 1 Available analysis types and relevant acquisition modes

\begin{tabular}{lcccc}
\hline $\begin{array}{c}\text { Analysis type } \\
\text { Acquisition mode }\end{array}$ & $\begin{array}{c}\text { Modal } \\
\text { analysis }\end{array}$ & $\begin{array}{c}\text { Liberation } \\
\text { analysis }\end{array}$ & $\begin{array}{c}\text { Bright phase } \\
\text { search }\end{array}$ & $\begin{array}{c}\text { Section } \\
\text { analysis }\end{array}$ \\
\hline High-resolution & $\times$ & $\times$ & $\times$ & $\times$ \\
mapping & & $\times$ & $\times$ & $\times$ \\
Point spectroscopy & $\times$ & & $\times$ \\
Line mapping & $\times$ & $\times$ & $\times$ \\
Dot mapping & & & &
\end{tabular}


ping" (see Section 2.4.1). It can be applied to particulate material or thin sections and polished blocks to obtain statistically robust modal data. It is in a way similar to classical point counting (Glagolev 1934; Larrea et al. 2014 and references therein), but is able to collect more than 500 analytical points per second!

\subsubsection{TIMA Liberation Analysis (TLA)}

In the Liberation analysis (Fig. 5), the EDS data are collected simultaneously with the BSE or in the subsequent phase depending on the acquisition mode. In general, the Liberation analysis can be customized to provide a very versatile tool for collecting statistically robust data on modal and textural characteristics of the sample. The patented segmentation algorithm (Section 2.3 above) combines the BSE and X-ray spectral information from similar points in a grid automatically into clusters (zones of coherent BSE and EDS data). The EDS data from the measurement points inside each grain/segment are summed to produce high-quality spectra. The mean BSE level for each grain/segment and the combined spectrum are used to classify the segments and form grains using the specified classification scheme to determine the mineral/phase identity. The raw unsegmented data are saved and can be re-segmented later off-line. This enables the user to develop more advanced algorithms for phase segmentation and clustering even for the most complex samples (Hrstka et al. 2017a, b).

\subsubsection{TIMA Bright Phase Search (TBPS)}

This mode is a specific instance of the liberation analysis that is optimized to search for phases (usually scarce) with a specific BSE signal, chemical composition, or both. It adds an extra step of initial assessment of the phase as a phase of interest either based on a BSE value, or on a single spectrum, i.e. phase identification based on a certain "classification scheme" (phase filtering). This provides optimum results for search for specific phases of interest as demonstrated in some previous studies (Haluzová et al. 2015; Slavík et al. 2016). There is also a parameter to decide whether the entire host particle should be subjected to EDS analysis or if only a certain area around the grain of interest is analyzed (Fig. 6). This provides the means of analyzing specific grains within thin sections or large particles and include the relevant textural/association/locking data. It can dramatically speed up the analysis in such scenarios. If required, BSE images of the whole sample can be also collected simultaneously in order to understand the general textural context.
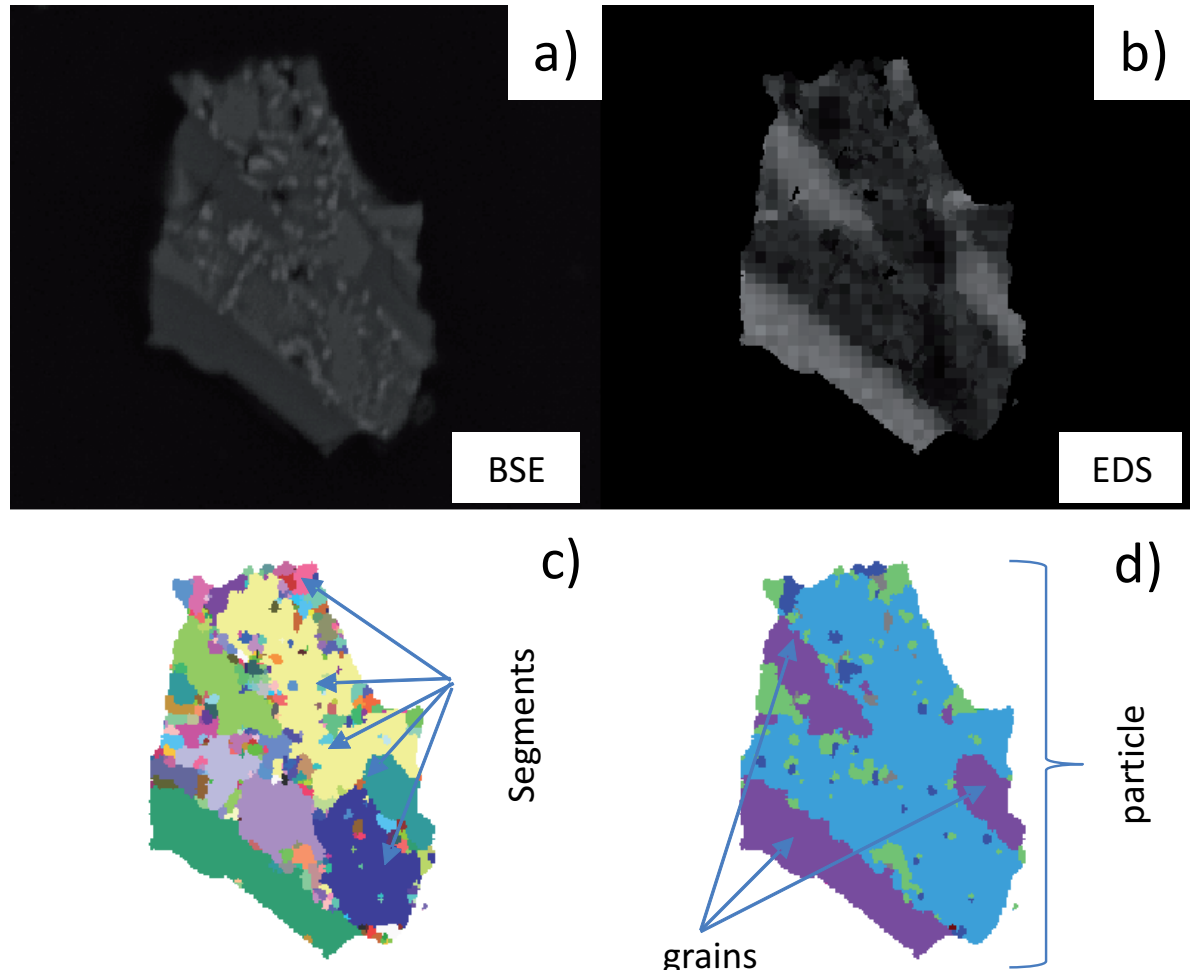

Segmentation

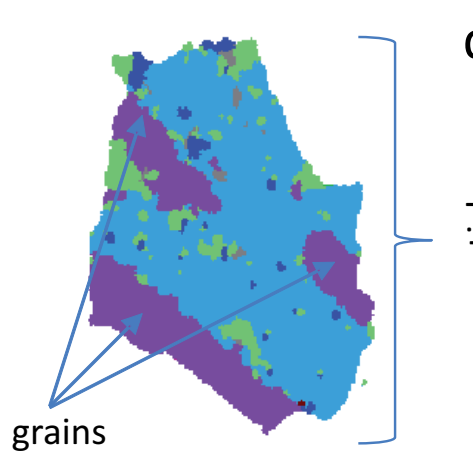

Mineral Map d) a solid rock.

Fig. 5 Individual steps of TIMA Liberation analysis with dot mapping mode - BSE image at $0.3 \mu \mathrm{m}$ (a) and EDS data at $1.5 \mu \mathrm{m}(\mathbf{b})$ are combined by an algorithm to produce pools of coherent BSE and EDS data/segments (c). Energy-dispersive data from each pixel within a segment are summed to produce one high-quality spectrum (suitable for quantitative EDS analysis). The average BSE intensity is also calculated. Data from each segment are then compared against the classification scheme and mineral map is created (d). 


\subsection{Data analysis and presentation}

In addition to the measurement capabilities, the TIMA software enables saving the measurements/data in a da- tabase structure, to view them interactively, to process them, analyze and create reports to present the quantitative mineralogical and petrological information generated by the TIMA measurements. Image data (currently BSE,

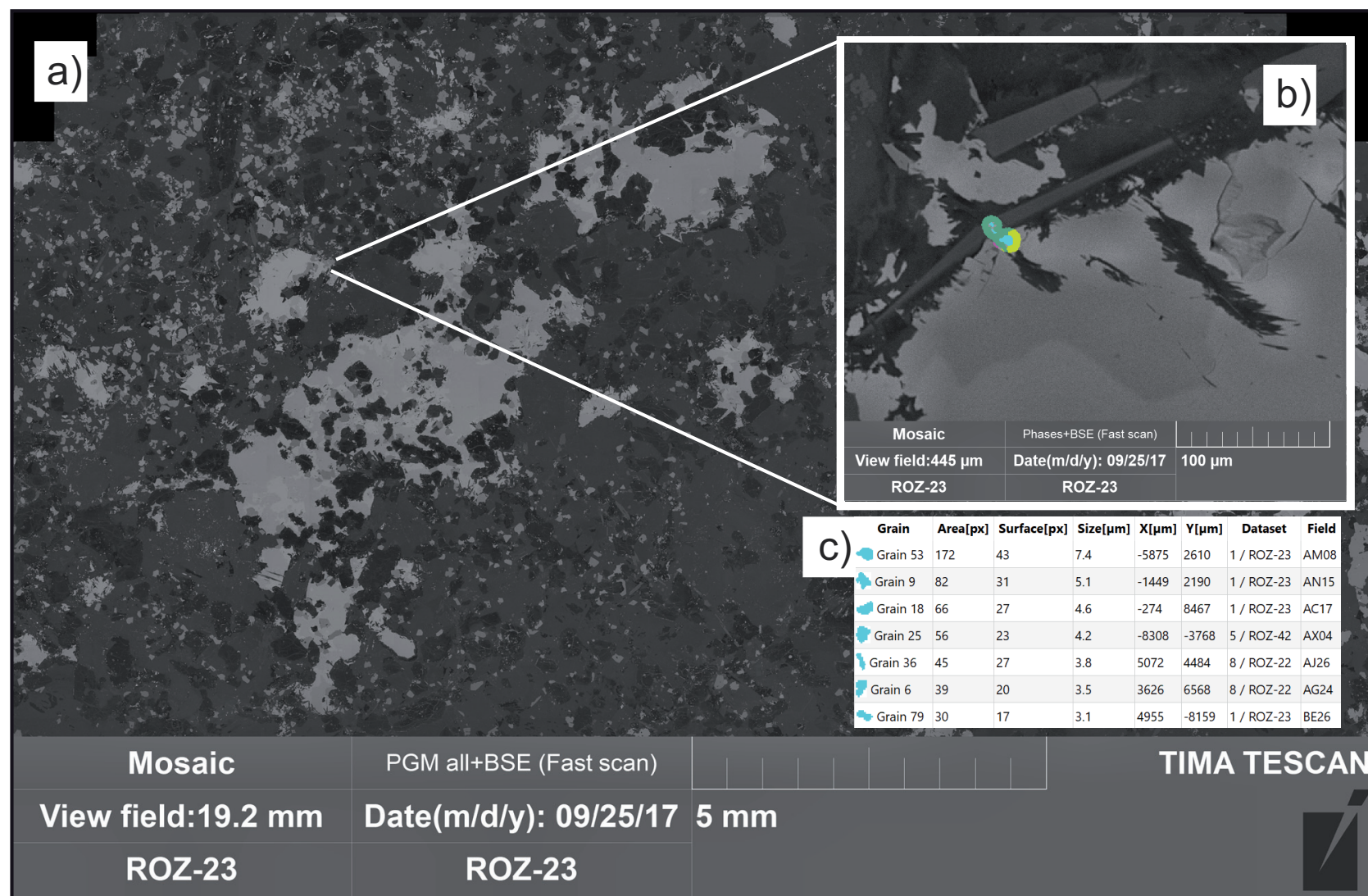

\begin{tabular}{|c|c|c|c|c|}
\hline PGM all - CzFin / Volume of phase [px] & $\mathrm{ROZ}-23$ & $\mathrm{ROZ}-42$ & ROZ-22 & ROZ-32 \\
\hline Copper sulfides & 12757 & 10779 & 1174 & 16528 \\
\hline Iron oxides & 17716 & 1043 & 2369 & 304 \\
\hline - Sulfides & 292 & 0 & 0 & 0 \\
\hline Galena & 29438 & 34745 & 5217 & 74412 \\
\hline - Pyrrhotite & 7025 & 10690 & 4540 & 13604 \\
\hline$\equiv$ Pentlandite & 4456 & 2315 & 4805 & 6101 \\
\hline - Pyrite & 117778 & 0 & 5291 & 0 \\
\hline Oxides & 1073 & 733 & 580 & 32 \\
\hline Carbonates & 9 & 4686 & 0 & 12785 \\
\hline Phosphates & 4973 & 5616 & 157 & 2970 \\
\hline - Silicates & 398602 & 614168 & 103124 & 315013 \\
\hline - SpinelQ & 156 & 22 & 19 & 0 \\
\hline$\boxplus$ PGM all & 795 & 151 & 269 & 145 \\
\hline Other minerals & 30054 & 36443 & 6306 & 48577 \\
\hline Holes & 532 & 1727 & 119 & 307 \\
\hline Total & 625656 & 723118 & 133970 & 490778 \\
\hline
\end{tabular}

\begin{tabular}{|l|r|r|r|r|}
\hline PGM all - CzFin / Number of grains of phase & ROZ-23 & ROZ-42 & ROZ-22 & ROZ-32 \\
\hline - Copper sulfides & 109 & 114 & 8 & 90 \\
\hline - Iron oxides & 181 & 16 & 20 & 6 \\
\hline - Sulfides & 4 & 0 & 0 & 0 \\
\hline - Galena & 1059 & 1519 & 186 & 582 \\
\hline - Pyrrhotite & 38 & 45 & 19 & 79 \\
\hline - Pentlandite & 59 & 29 & 18 & 49 \\
\hline - Pyrite & 152 & 0 & 4 & 0 \\
\hline - Oxides & 16 & 4 & 2 & 1 \\
\hline - Carbonates & 1 & 89 & 0 & 149 \\
\hline - Phosphates & 25 & 29 & 1 & 10 \\
\hline - Silicates & 1200 & 1349 & 248 & 769 \\
\hline - SpinelQ & 12 & $\mathbf{1}$ & $\mathbf{1}$ & 0 \\
\hline - PGM all & 43 & 13 & 19 & 7 \\
\hline - Other minerals & 1381 & 2130 & 281 & 1438 \\
\hline Holes & $\mathbf{6 7}$ & $\mathbf{6 6}$ & $\mathbf{2 5}$ & $\mathbf{2 5}$ \\
\hline Total & $\mathbf{4 3 4 7}$ & $\mathbf{5 4 0 4}$ & $\mathbf{8 3 2}$ & $\mathbf{3 2 0 5}$ \\
\hline
\end{tabular}

Fig. 6 Specific mineral search in thin sections from the Ni-Cu-(PGE) mineralization at Rožany, Czech Republic. a - Example of a thin section covered by 904 individual fields with $600 \mu \mathrm{m}$ field width (resolution of $0.5 \mu \mathrm{m}, 5000$ counts per point and $5 \mu \mathrm{m}$ neighborhood size). This measurement identified $\sim 2000$ potential targets on a single thin section and automatically identified 43 PGM grains. Summed EDS spectra provided their composition and exact coordinates for navigation of the consequent EMPA analysis. b - Zoomed area with three PGM grains with their surrounding minerals being analyzed to provide association/locking data (e.g. presence in sulfides, silicates or on the grain boundaries). c - Selected particles of PGM with information on their area, size and position within the sample. $\mathbf{d}$ - Statistical data on the number of individual minerals analyzed during the automated search and the area (volume of phases in pixels) of each mineral group. 
SE and CL) are combined with the elemental composition and densities of the identified phases/minerals on a pixel by pixel (or segment by segment) basis to produce a variety of mineralogical data. There are several predefined reports/data analysis tools that are available; the information they provide is nearly self-explanatory:

- Panorama, Fields, Particle viewer, and Grain view are used to visualize the images of grains, particles, individual analyzed fields or whole samples.

- Mineral association, Mineral liberation, Mineral locking, Mineral release, Grain size Phase SSA, Porosity and Particle constituents are designed to provide values related to textural analysis of the samples. For the examples of textural analysis reader is referred to e.g. Lastra (2007) or Pérez-Barnuevo et al. (2013).

- Elemental Mass, Elemental deportment and Mineral Mass provide results on modal distribution of minerals/phases and the distribution of elements between individual phases/minerals. The performance of a theoretical perfect concentrator is given by the Grade-Recovery report. It is used to compare with the actual performance of a mineral concentrator plant and asses its efficiency. See Lotter et al. (2011) and Altree-Williams et al. (2015) for more details on the use of grade-recovery data.

An important type of report is the Assay reconciliation that provides a QA check against an independent chemical assay of a sample. If a representative sample is selected, then two aliquots can be made. The first is measured by TIMA and the modal mineralogy is combined with the mineral chemistries and densities to calculate a theoretical elemental assay of the sample. The calculated assay is compared to the XRF, ICP-MS or any other independent bulk chemical analysis of the other representative aliquot. Very good reconciliation can be achieved but some potential pitfalls related mainly to the sampling statistics and the quality of the preparation of the samples were identified and discussed in literature (Hrstka 2008, 2012; Johnson et al. 2015; Lastra and Paktunc 2016; Pooler and Dold 2017).

Measurement properties report tabulates measurement parameters such as the measurement type, acquisition mode, pixel spacing with operational statistical values such as measurement time, area, number of fields, number of particles and number of analytical points acquired.

There are also general-purpose reports, which include the Generic output, Particle category and Category view$e r$. Each of them can be customized for a particular purpose by using mineral particle and elemental properties from the measured data in expressions and queries. These reports represent the full potential of the AM systems.

\subsection{User-defined expressions and queries}

User-defined expressions are used for particle classification, filtering and sorting. This provides the best opportunity to explore the data for any specific research project and create outputs based on categorizers. Examples could be plotting drilling log data from several samples studied during a drilling campaign, geological mapping, provenance study, creating complex tables for dashboards and interactive real-time work with data.

\subsubsection{Expressions and queries}

The TIMA software has the ability to select multiple subsets of measured data from the database by user-defined queries. The syntax is somewhat similar to a Structured Query Language (SQL) approach but is specifically tailored to AM requirements.

Queries can be used to extend capabilities of the existing predefined reports or to create new specific custom reports. The query can be understood as a function that derives a statistics from a (sub-) population of objects, for example total mass of a phase. Depending on the report type, the statistic assessment is applied to all selected measurements or a subpopulation thereof classified using the categorizer or created by filtering of a certain type of objects. This is a highly customizable way to explore the data and to provide appropriate interpretation suitable for every specific mineralogy/petrology research or industry driven task. A suitable example could be looking at the deportment/distribution of a certain element among different mineral phases or even individual lithotypes present in the sample.

\subsubsection{Filtering}

Filters are used to create an object (e.g. particle or mineral grain) sub-set for subsequent inclusion in the computation and display of images, tables and charts. A filter can be as simple as manually including or excluding a sub-set of measurements or it can be more complex, based on user-defined criteria.

Multiple object properties can be combined in a filter through expressions or through a selection of multiple filters from a pre-defined table. Multiple filters are a form of the logical AND operator; an object must pass all the conditions in a filter group (referred to as "expression") to be included.

An example of application is the location of grains of zircons in a heavy minerals grain mount for later analysis by e.g. EPMA or LA-ICP-MS. A multiple filter can easily be defined to show particles with zircon grains larger than $30 \mu \mathrm{m}$ (e.g. combined size (size>30) and phase (MineralPercent (Zircon) >90). It can also be 
used to exclude some artefacts from the measurements based on their size, composition and/or shape. Filtering is also very useful for interactive work where it can be used to focus onto a small subset of relevant information (e.g., particles with density $>3 \mathrm{~g} / \mathrm{cm}^{3}$ and size $>100 \mu \mathrm{m}$ ).

\subsubsection{Sorting}

Sorting allows the user to arrange objects (e.g. particles or grains) based on their properties. It allows the user to visualize particles based on their size, mineral or element contents, density or other parameters. This is particularly useful while performing the quality control on the results or for understanding data present in calculations visually. An example would be to sort all the zircon grains found in a thin section by their size or sort all the grains found based on their density to evaluate the phases likely allowing the LA-ICP-MS dating. Another example would be to sort all the particles/grains by element mass, or phase mass to see the most important carriers of a certain element/phase in the tested sample (e.g. to evaluate the possible nugget effect of one big grain hosting most of a certain element).

\subsubsection{Categorizing}

Unlike the filters that are used to exclude particles/data from charts, tables and visualization the categorizers are employed to subdivide the data into user-defined categories (classes). Each category is defined by a set of rules, based on properties of the data objects (e.g. particle size, liberation, phase contents, elemental content etc.). Combinations of rules of different kind are also possible. Categories are now used only in specific report types. A simple example would be to create individual sub-groups of particles based on their textural properties like liberation or association. (e.g., Area \% (Mineral) $>=80<=100$, Area (Mineral) $>=60$ $<=80$, Area $\frac{0}{\text { (Mineral) }}>=20<=60$, Area $\div$ (Mineral) $>0<=20$ ). For particulate samples this would create classes of nearly free (liberated) mineral of interest, relatively liberated mineral of interest, mixed particles composed of mineral of interest and other phases and particles with low proportion of the mineral of interest. While liberation or association information are mostly used in mineral processing to model the theoretical behavior of particles in a physical separation unit like cyclone or flotation cell (Sandmann and Gutzmer 2013; Jordens et al. 2016) the same concept can be easily extended to classifying the rock fragments or thin sections according to their petrological classification ("lithotyping") (Haberlah et al. 2010; Knappett et al. 2011; Higgs et al. 2015). Automated classification according to the QAPF classification scheme for igneous rocks (Le Maitre 2002) can be an excellent example. As we can use the combined modal and textural criteria at the same time for categorizing, this approach of automated rock type classification can be also adopted for sedimentary and, to a certain degree, even to metamorphic rocks.

\subsubsection{Mineral grouping}

As the list of phases/minerals identified in a sample can be quite extensive, a grouping function allows a mineral group to be defined and further treated as individual mineral phase (e.g. all feldspars, all amphiboles, all silicates, all heavy minerals etc.). Minor minerals of little importance to an analysis could be automatically grouped as "other" based on a minimal mass in the sample threshold. Several groupings with different level of detail for classification of minerals/phases (e.g. species, series, subgroups, groups) can be used at the same time to simplify the navigation through data or results reporting (e.g. detailed grouping for modal analysis and simplified grouping for textural/petrographic analysis).

\section{Case studies}

The many measurement types and acquisition modes of the TIMA system were tested at the Institute of Geology of the Czech Academy of Sciences in numerous scientific projects in areas spanning from ore geology (Haluzová et al. 2015), through paleontology and paleoecology (Slavík et al. 2016), petrology (Svojtka et al. 2016; Žák et al. 2016; Ackerman et al. 2017; Breiter et al. 2017, 2018), archaeology (Neumannová et al. 2016), ecology/contaminated soil analysis (Harvey et al. 2017) to dust analysis (Hrstka et al. 2017b). The majority of the applications have been linked to the fast collection of statistically robust data on mineral composition and textural characteristics, together with the ability to quickly search for specific minerals or phases within geological samples. To illustrate the novel approach of Dot map (TDM) analysis and Bright phase search (TBPS) in thin sections (specific mineral search), selected case studies on applications of the TIMA AM technology are briefly outlined in this section.

\subsection{Case study 1 - fast automated search for specific minerals in thin and polished sections}

The modal analysis in combination with Bright phase search (TBPS) was used to provide better constraints on the nature, conditions of formation and evolution of sulphide mineralization at Rožany deposit, northernmost Bohemian Massif (Haluzová et al. 2015). Studied samples were collected in two abandoned quarries (the first 
quarry: N 51⒉09'; E 14²7.08', the second: N 51 $2.05^{\prime}$; E $\left.14^{\circ} 27.87^{\prime}\right)$ in 2014-2015. In total, six samples of massive ores, two of disseminated ores and one of the barren dolerite were selected from a large sample collection. These were used to investigate the mineralogy and characteristics of the $\mathrm{Ni}-\mathrm{Cu}-(\mathrm{PGE})$ mineralization.

The distribution of the individual platinum-group minerals (PGM) was established through the detailed "TBPS" analysis. For the eight studied samples, over 29,000 potential target grains $(0.5-200 \mu \mathrm{m}$ in size $)$ were identified based on the BSE brightness. By matching the EDS signature to the classification scheme, 63 PGM grains were located in less than $10 \mathrm{~h}$. Their identification through the automated system was crosschecked by a detailed manual SEM/EMPA investigation of selected individual grains located through the TIMA analysis. The correlative TIMA workflow allowed exporting the co-ordinates of target grains into the EPMA system. In addition to the previous studies, minerals moncheite $\left[(\mathrm{Pt}, \mathrm{Pd})(\mathrm{TeBi})_{2}\right]$ and michenerite $[(\mathrm{Pd}, \mathrm{Pt}) \mathrm{BiTe}]$ were revealed and a possible unnamed $\mathrm{Pt}-\mathrm{As}-\mathrm{Te}$ phase was also noted. During the TIMA investigation the PGM were found not only directly in the base-metal sulphides or at sulphide-silicate grain boundaries, but also in matrix silicates, amphiboles and/or chlorites. This indicates that at least part of the PGM was related to the late-stage hydrothermal processes.

The distribution of the individual PGE was shown to correlate with the likely incorporation of Iridium group of PGM (I-PGM) in Ni-bearing sulphides in the form of solid solution. The results are in agreement with the findings of Sandmann and Gutzmer (2015) indicating that high number of polished sections needs to be studied to provide statistically valid data on PGM distribution. The automated approach enabled fast localization and identification of PGM among the BSE-bright phases within the samples. It also helped to assess the economic potential of the deposit and to constrain the ore genesis in comparison with other $\mathrm{Ni}-\mathrm{Cu}-(\mathrm{PGE})$ mineralizations (Haluzová et al. 2015).

\subsection{Case study 2 - palaeoecological characterization of the Lochkovian- Pragian boundary}

A highly automated approach was used in the paleoecological characterization of the sedimentary record across the Lochkovian-Pragian boundary in the Spanish Central Pyrenees to explain the origin of the anomalously high (17 to $26 \mathrm{ppm}$ ) Th contents in this stratigraphic interval as well as to better understand the potential source areas and provenance of impurities in the carbonates (Slavík et al. 2016). In this case the use of AM allowed us to trace the source of Th and identify monazite as its main carrier.
Also the spatial distribution of magnetite in the samples was used to shed some light on the magnetostratigraphic properties of the rocks.

The TIMA has found over a thousand monazite grains, $1-80 \mu \mathrm{m}$ across, some displayed a complex inner structure formed by visible relict nuclei crystals or crystoclasts rich in Th, surrounded by altered overgrowths with a spongy or crystalline appearance considerably depleted in Th. The outermost rims were again enriched in Th. From the detailed analysis of individual monazite grains, the identified textures and comparison to similar material from other locations worldwide, understanding on the paleoclimate and its evolution was improved (Slavík et al. 2016 and references therein). Based on this published example, automated mineralogy data together with systematic specific mineral search and related deportment of elements of interest in thin sections and rock samples offers wide and promising applications in identification of source areas, paleoclimate reconstructions and provenience studies in general.

\subsection{Case study 3 - Cínovec/Zinnwald Pluton, Krušné Hory Mts./Erzgebirge}

The $1597 \mathrm{~m}$ deep borehole CS-1 located in the center of the Cínovec Pluton represents an ideal object for evaluation of vertical structure of rare-metal bearing magmatic systems (Štemprok and Šulcek 1969; Štemprok 2016; Breiter et al. 2017).

A combination of textural and chemical methods was applied to the whole-rock and mineral samples to define chemical and mineral composition of all granite facies and to assess the relative role of magmatic and metasomatic processes during differentiation of the pluton and formation of the Cínovec/Zinnwald Li-Sn greisen deposit.

One of the tasks was the estimation of temperature of crystallization of the main granite facies using feldspar geothermometer (Whitney and Stormer 1977).

The Cínovec Pluton is composed of two principal units: a suite of albite-zinnwaldite granites forms upper part to the depth of $735 \mathrm{~m}$, whereas the suite of biotite granites follows in interval 735-1597 m. Both suites locally comprise fine-grained distinctly porphyritic facies (traditionally termed as microgranites) with perthite phenocrysts $5-10 \mathrm{~mm}$ in size.

To calculate the primary perthite composition and estimate the temperature of its crystallization, typical samples of both microgranites (zinnwalditic from the depth of $413 \mathrm{~m}$ and biotitic from the depth of $880 \mathrm{~m}$ ) were selected. The surface of thin section was divided into a square grid (c. 300 squares per a standard section) and the abundances of $\mathrm{Ab}$ and $\mathrm{Kfs}$ in each square were measured using TIMA. The results of the squares composed only of perthite were highlighted, and carefully inspected to verify if all of the albite really represented perthite ad- 

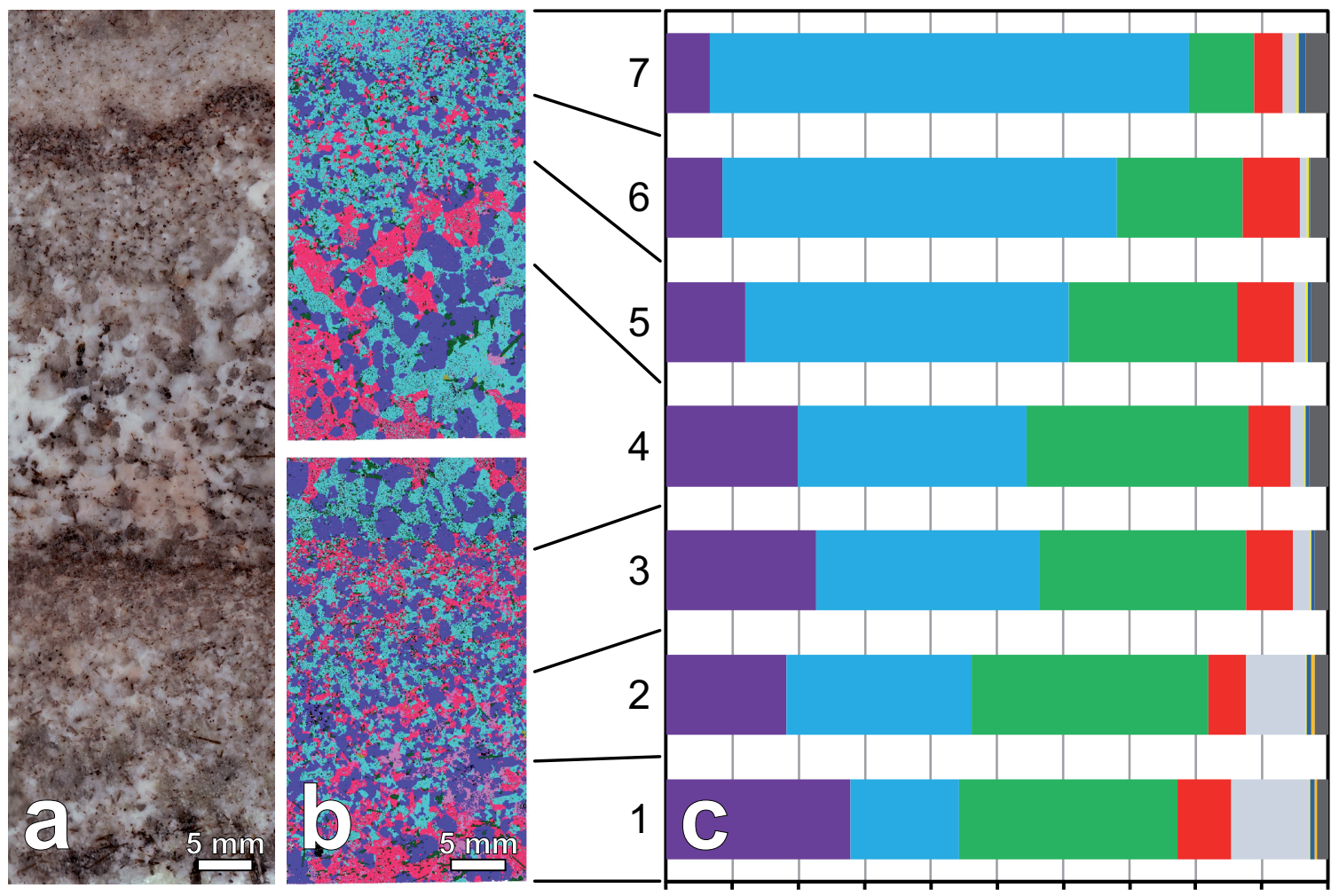

- Kfs

- Ab

- Qz

- Tur

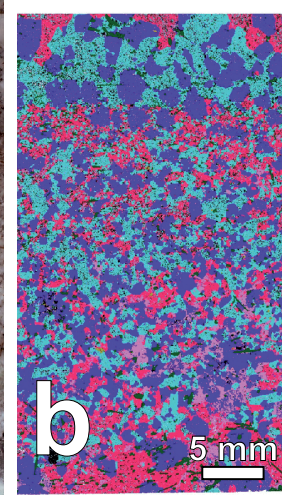

Ms

Znw

- Ap

- Tpz

- Rest

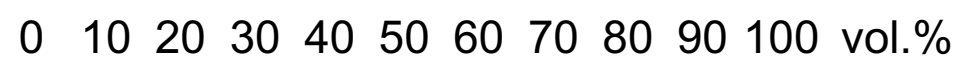

Fig. 7 Detailed investigation of a fine-grained layered rock (Megiliggar, Cornwall): a - Macro-photo; b - Mineral map by TIMA; $\mathbf{c}-$ Modal composition of individual layers. Mineral abbreviations after Whitney \& Evans (2010). Crystallization of the rock proceeded upwards.

mixtures. After the exclusion of all squares containing also the likely primary albite, the mean composition of perthite within the section was calculated. The primary composition of the alkali feldspars was obtained on the basis of modal abundances of the K- and Na-phases and their chemical compositions measured by the EMPA. The calculated $\mathrm{Ab}$ component in primary feldspar decreases from c. $40 \%$ in the biotite microgranite $(\mathrm{BtGm})$ at the depth of $860 \mathrm{~m}$ to $c .21 \%$ in the zinnwaldite microgranite $(\mathrm{ZiGm})$ at the depth of $413 \mathrm{~m}$. Considering the decrease in pressure during magma ascent in the Eastern Erzgebirge $(6 \rightarrow 1$ kbar; Müller et al. 2005) and the primary composition of associated plagioclase $\left(\mathrm{An}_{15}\right.$ in the $\mathrm{BtGm}$ and $\mathrm{An}_{05}$ in the $\mathrm{ZiGm}$ ), the temperature of the perthite equilibration decreases upwards from approximately $800^{\circ} \mathrm{C}$ to $550^{\circ} \mathrm{C}$. In this case the automated collection of modal and textural data allowed better understanding of the granite evolution as detailed in Breiter et al. (2017).

\subsection{Case study 4 - estimation of mineral and chemical composition of layered aplite-pegmatite dykes: "line rocks" of Megiliggar, Cornwall}

Genetic relation between granitic pegmatites and granites, i.e. a search for the source of particular pegmatite body in some neighboring granite pluton, is the topic of a long-term debate (London 2008). Despite intense search, localities enabling to study the direct transition from granite pluton to rare-element pegmatite dykes are scarce. One of the best examples is the Megiliggar Rock at the SE contact of the Tregonning Granite in Cornwall, SW England (Stone 1969). Spectacular outcrops in the coastal cliff show the transition from the granite pluton through dyke leucogranites to aplites and pegmatites. The TIMA was used for a detailed study of the modal and chemical compositions of layered parts of the dykes, where the thickness of individual layers varies between 1 and $5 \mathrm{~mm}$ (Breiter et al. 2018).

Mineral maps across the zoning were constructed and mineral compositions in texturally distinct layers computed using the TIMA technology (Fig. 7). Prior mapping, typical EDS spectra of all analysed minerals were collected directly from the studied thin sections which substantially improved classification of different varieties of micas and other less common minerals.

Modal composition from part of one of the measured profiles is shown in Tab. 2 and Fig. 7. Modal composition of the sequence evolved systematically by the decrease in K-feldspar ( $28 \rightarrow 6.5$ vol. \%), quartz $(33 \rightarrow 10$ vol. \%), and muscovite $(12 \rightarrow 2$ vol. \%), along with a strong increase in albite $(16 \rightarrow 72$ vol. \%). Contents of Qtz, Kfs and Ms 
Tab. 2 Modal and computed chemical compositions of the individual aplite layers from Megiliggar (Cornwall) (vol. \% resp. wt. \%)

\begin{tabular}{|c|c|c|c|c|c|c|c|}
\hline Layer \# & 1 & 2 & 3 & 4 & 5 & 6 & 7 \\
\hline Orthoclase & 27.86 & 18.18 & 22.60 & 19.81 & 11.90 & 8.39 & 6.52 \\
\hline Albite & 16.39 & 27.94 & 33.79 & 34.67 & 49.02 & 59.77 & 72.43 \\
\hline Quartz & 32.96 & 35.74 & 31.16 & 33.53 & 25.24 & 18.97 & 9.90 \\
\hline Schorl & 8.14 & 5.68 & 7.13 & 6.36 & 8.75 & 8.57 & 4.33 \\
\hline Muscovite & 11.77 & 9.08 & 2.57 & 2.10 & 1.65 & 1.16 & 2.00 \\
\hline Zinnwaldite & 0.11 & 0.09 & 0.14 & 0.15 & 0.33 & 0.21 & 0.30 \\
\hline Apatite & 0.68 & 0.81 & 0.55 & 0.54 & 0.60 & 0.29 & 1.12 \\
\hline Topaz & 0.40 & 0.51 & 0.00 & 0.01 & 0.01 & 0.00 & 0.01 \\
\hline Fluorite & 0.06 & 0.09 & 0.09 & 0.10 & 0.11 & 0.12 & 0.16 \\
\hline Rutile & 0.00 & 0.00 & 0.00 & 0.02 & 0.00 & 0.00 & 0.00 \\
\hline Columbite & 0.00 & 0.00 & 0.00 & 0.00 & 0.00 & 0.00 & 0.00 \\
\hline Zircon & 0.00 & 0.01 & 0.01 & 0.01 & 0.01 & 0.02 & 0.00 \\
\hline Sum & 98.37 & 98.13 & 98.04 & 97.29 & 97.62 & 97.50 & 96.79 \\
\hline $\mathrm{SiO}_{2}$ & 71.06 & 73.34 & 72.99 & 73.65 & 70.92 & 69.41 & 66.64 \\
\hline $\mathrm{TiO}_{2}$ & 0.15 & 0.11 & 0.06 & 0.06 & 0.06 & 0.05 & 0.04 \\
\hline $\mathrm{Al}_{2} \mathrm{O}_{3}$ & 15.15 & 13.92 & 13.81 & 13.07 & 15.10 & 16.27 & 17.22 \\
\hline $\mathrm{FeOt}$ & 1.36 & 0.97 & 1.03 & 0.92 & 1.25 & 1.20 & 0.66 \\
\hline $\mathrm{MgO}$ & 0.05 & 0.04 & 0.04 & 0.04 & 0.05 & 0.05 & 0.03 \\
\hline $\mathrm{MnO}$ & 0.04 & 0.04 & 0.03 & 0.03 & 0.03 & 0.02 & 0.04 \\
\hline $\mathrm{CaO}$ & 0.42 & 0.52 & 0.40 & 0.40 & 0.46 & 0.32 & 0.79 \\
\hline $\mathrm{Li}_{2} \mathrm{O}$ & 0.00 & 0.00 & 0.00 & 0.01 & 0.01 & 0.01 & 0.01 \\
\hline $\mathrm{Na}_{2} \mathrm{O}$ & 2.17 & 3.45 & 4.19 & 4.27 & 5.99 & 7.24 & 8.65 \\
\hline $\mathrm{K}_{2} \mathrm{O}$ & 6.06 & 4.12 & 4.17 & 3.64 & 2.28 & 1.63 & 1.43 \\
\hline $\mathrm{Rb}_{2} \mathrm{O}$ & 0.08 & 0.06 & 0.06 & 0.05 & 0.03 & 0.02 & 0.02 \\
\hline $\mathrm{P}_{2} \mathrm{O}_{5}$ & 0.31 & 0.37 & 0.26 & 0.26 & 0.28 & 0.16 & 0.51 \\
\hline $\mathrm{B}_{2} \mathrm{O}_{3}$ & 0.81 & 0.56 & 0.71 & 0.63 & 0.87 & 0.85 & 0.43 \\
\hline $\mathrm{F}$ & 0.26 & 0.26 & 0.09 & 0.09 & 0.11 & 0.09 & 0.13 \\
\hline Sum & 96.85 & 96.95 & 97.04 & 96.39 & 96.46 & 96.38 & 96.03 \\
\hline
\end{tabular}

\section{Qtz}

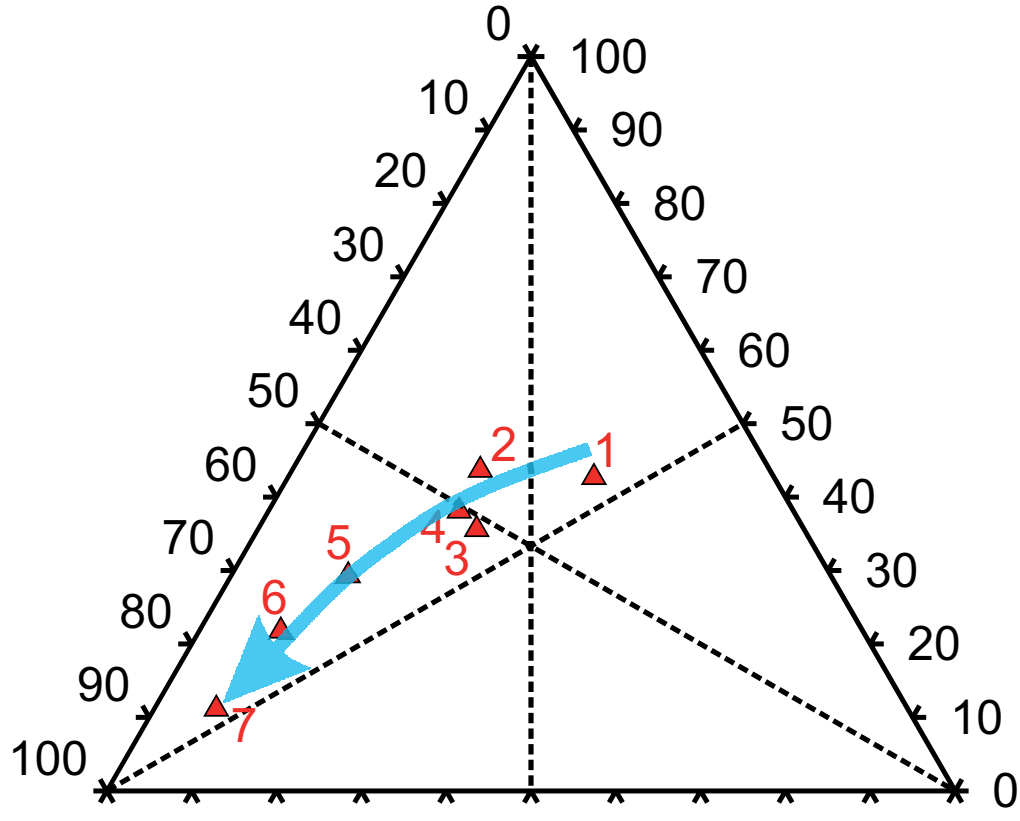

systematically decrease, while the content of $\mathrm{Ab}$ increases upwards in the profile, i.e. in the direction of crystallization. Within the Qtz-Ab-Kfs triangle (Fig. 8), a shift of the rock composition from Qtz + Kfs-dominated to $\mathrm{Ab}$-dominated, i.e. in direction of common evolution of leucogranitic melts, is clear.

Approximate chemical compositions of individual layers were computed from modal compositions and chemistries of rock-forming minerals analyzed by the microprobe (Li by LAICP MS) (Tab. 2). The chemical composition of the whole layered sequence should be calculated as a mean of the compositions of individual layers, taken into account their relative thickness. This method enabled, among others, to compute contents of chemical elements difficult to analyze, such as boron. The automated approach with fast modal analysis and good textural resolution significantly shortened the time needed for mapping of large areas of the petrological samples.

\section{Discussion and future developments}

The goal of the ongoing TIMA$\mathrm{X}$ development is to provide a comprehensive automated mineralogy tool with increasing level of automation, through the integration of artificial intelligence and expert-guided machine learning. The current system is a highly specialized automated SEM providing excellent tool for geosciences and material science in general. For

Fig. 8 Composition of individual layers of lined rocks (Megiliggar, Cornwall) in the $\mathrm{Ab}-\mathrm{Qtz}-\mathrm{Kf}$ triangle. Note the systematic shift to the $\mathrm{Ab}$-apex from the point 1 to 7 . 
further improvements of the AM technology there are still number of topics which can be addressed.

From the instrumentation perspective: further speeding up of data acquisition, and better integration of additional detectors providing extended input of information (Raman, WDS, cathodoluminescence, and micro-XRF) might be useful.

From the software perspective: parallelization in data processing and integration of big data concepts could provide significant advantage while working on projects with hundreds or thousands of samples. Also the correlative microscopy approach helping to integrate data from other techniques and above-mentioned potential new detectors will be highly beneficial. In the short term, the integration of more sophisticated textural parameters is under development.

Automated classification file construction through the means of artificial intelligence, neural networks, principal component analysis (PCA), machine learning, similarity search and hierarchical clustering is also a matter of interest (Hrstka et al. 2017a). The implementation of standards for cross-correlation between different instruments would be also highly desirable in the future. This seems particularly important as more AM systems are being developed and there has been very little research comparing their analytical capabilities so far.

\section{Conclusions}

Combined use of all available signals (mainly BSE and EDS) in conjunction with advanced image and patternrecognition analysis involving artificial intelligence are required for any modern automated SEM-based mineral analysis system. Such systems can be used not only in their classic domain of mineral processing, plant monitoring, optimization and design but can provide valuable information in a broad variety of Earth and material sciences. We have demonstrated the high potential of TIMA in extending the everyday tools for geoscience research by a number of case studies. We have also shown that the new generation of automated mineralogy instruments builds on the original concepts introduced in the early 1970's but provides additional benefits due to the improvements in analysis modes, full integration of quantitative EDS and availability of computation power and complex programing.

Acknowledgements. We are indebted to Rolando Lastra, Jens Gutzmer, Rogerio Kwitko Ribeiro and the editors for the review. Their comments and suggestions on the manuscript greatly improved the final text. We would also like to thank TESCAN for the support of the TIMA application laboratory at Institute of Geology of the CAS, v. v. i. This study was financed also through Strategie
AV21/4 project and with help of Institute of Geology of the CAS, v. v. i. research plan RVO 67985831. Finally, we would like to thank SGS Minerals for their support of this study.

Electronic supplementary material. Supplementary data on mean atomic numbers of the selected minerals for this paper are available online at the Journal website (http://dx.doi.org/10.3190/jgeosci.250).

\section{References}

ACKERMAN L, MAgNA T, RAPPRICH V, UPADHYAY D, KrÁTKÝ O, Čejková B, Erban V, Kochergina YV, Hrstka $\mathrm{T}$ (2017) Contrasting petrogenesis of spatially related carbonatites from Samalpatti and Sevattur, Tamil Nadu, India. Lithos 284: 257-275

Altree-Williams A, Pring A, Ngothai Y, Brugger J (2015) Textural and compositional complexities resulting from coupled dissolution-reprecipitation reactions in geomaterials. Earth Sci Rev 150: 628-651

Andersen JCØ, Rollinson GK, Snook B, Herrington R, FAIRHURST RJ (2009) Use of QEMSCAN ${ }^{\circledR}$ for the characterization of Ni-rich and Ni-poor goethite in laterite ores. Miner Eng 22: 1119-1129

Berrezueta E, Ordóñez-Casado B, Bonilla W, Banda R, Castroviejo R, Carrión P, Puglla S (2016) Ore petrography using optical image analysis: application to Zaruma-Portovelo Deposit (Ecuador). Geosciences 6: DOI 10.3390/geosciences6020030

Breiter K, Ďurišová J, HrstKa T, Korbelová Z, VañKová M, VaŠInová Galiová M, KanickÝ V, RambouseK P, KNÉSL I, Dobeš P, DosbabA M (2017) Assessment of magmatic vs. metasomatic processes in rare-metal granites: a case study of the Cínovec/Zinnwald Sn-W-Li deposit, Central Europe. Lithos 292/293: 198-217

Breiter K, Ďurišová J, HrstKa T, Korbelová Z, VAŇKová M, Vašinová Galiová M, Müller A, Simons B, Shail RK, Williamson BJ, DaVies JA (2018) The transition from granite to banded aplite-pegmatite sheet complexes: an example from Megiliggar Rocks, Tregonning topaz granite, Cornwall. Lithos 302/303: 370-388

Donskoi E, Suthers SP, Fradd SB, Young JM, CAMPBell JJ, RAYNLYN TD, CLOUT JMF (2007) Utilization of optical image analysis and automatic texture classification for iron ore particle characterisation. Miner Eng 20: 461-471

FANDrich R, Gu Y, Burrows D, MoEller K (2007) Modern SEM-based mineral liberation analysis. Int J Miner Process 84: 310-320

Glagolev AA (1934) Quantitative analysis with the microscope by the point method. Eng Min J 135: 399-400

GotTlieb P (2008) The revolutionary impact of automated mineralogy on mining and mineral processing. In: WANG 
DZ, Sun CY, Wang FL, Zhang LC, Hang L (eds) $24^{\text {th }}$ International Mineral Processing Congress. Science Press, Beijing, pp 165-174

Gottlieb P, Wilkie G, Sutherland D, Ho-Tun E, Suthers S, Perera K, Jenkins B, Spencer S, Butcher A, Rayner $\mathrm{J}$ (2000) Using quantitative electron microscopy for process mineralogy applications. JOM 52: 24-25

Haberlah D, Williams MAJ, Halverson G, McTainsh GH, Hill SM, Hrstka T, Jaime P, Butcher AR, Glasby P (2010) Loess and floods: high-resolution multi-proxy data of Last Glacial Maximum (LGM) slackwater deposition in the Flinders Ranges, semi-arid South Australia. Quat Sci Rev 29:2 673-2693

Haluzová E, AcKerman L, PAŠAva J, JonÁŠová Š, SvoJTKa M, Hrstka T, Veselovský F (2015) Geochronology and characteristics of $\mathrm{Ni}-\mathrm{Cu}-(\mathrm{PGE})$ mineralization at Rožany, Lusatian Granitoid Complex, Czech Republic. J Geosci 60: 219-236

HARDING DP (2002) Mineral identification using a scanning electron microscope. Miner Metall Process 19: 215-219

Harvey PJ, Rouillon M, Dong C, Ettler V, Handley HK, Taylor MP, Tyson E, Tennant P, Telfer V, Trinh R (2017) Geochemical sources, forms and phases of soil contamination in an industrial city. Sci Total Environ 584-585: 505-514

Higgs KE, Haese RR, Golding SD, Schacht U, Watson MN (2015) The Pretty Hill Formation as a natural analogue for $\mathrm{CO}_{2}$ storage: an investigation of mineralogical and isotopic changes associated with sandstones exposed to low, intermediate and high $\mathrm{CO}_{2}$ concentrations over geological time. Chem Geol 399: 36-64

Hoal KO, Stammer JG, Appleby SK, Botha J, Ross JK, Botha PW (2009) Research in quantitative mineralogy: examples from diverse applications. Miner Eng 22: $402-408$

HrSTKA T (2008) Preliminary results on the reproducibility of sample preparation and QEMSCAN ${ }^{\circledR}$ measurements for heavy mineral sands samples. Ninth International Congress for Applied Mineralogy, proceedings: ICAM 2008. Australasian Institute of Mining and Metallurgy, Carlton (Vic), pp 107-111

Hrstka T (2012) Paleofluid Chemistry of Orogenic Gold Deposits: Novel Analytical Methods and Case Studies from the Bohemian Massif. Unpublished PhD thesis, Faculty of Science, Charles University in Prague, pp $1-151$

Hrstka T, Gottlieb P, Moravec J, Lokoc J (2017a) The future of SEM-based automated mineralogy and artificial intelligence in applied mineralogy. Sci Res Abstr 6: Digilabs, pp 42

Hrstka T, Motl D, Gottlieb P, Hladil J (2017b) Using an automated approach in building a dust particle atlas for research and environmental monitoring. Sci Res Abstr 6: Digilabs pp 43
Johnson C, Pownceby MI, WiLson NC (2015) The application of automated electron beam mapping techniques to the characterisation of low grade, fine-grained mineralisation; potential problems and recommendations. Miner Eng 79: 68-83

Jordens A, Marion C, Grammatikopoulos T, Waters KE (2016) Understanding the effect of mineralogy on muscovite flotation using QEMSCAN. Int J Miner Process 155: 6-12

Knappett C, Pirrie D, Power Mr, Nikolakopoulou I, Hilditch J, Rollinson GK (2011) Mineralogical analysis and provenancing of ancient ceramics using automated SEM-EDS analysis $\left(\mathrm{QEMSCAN}^{\circledR}\right)$ : a pilot study on LB I pottery from Akrotiri, Thera. J Archaeolog Sci 38: 219-232

Kwitko-Ribeiro R (2012) New sample preparation developments to minimize mineral segregation in process mineralogy. In: Broekmans MATM (ed) Proceedings of the $10^{\text {th }}$ International Congress of Applied Mineralogy. Springer, Berlin, Heidelberg, pp 411-417

Lane GR, Martin C, Pirard E (2008) Techniques and applications for predictive metallurgy and ore characterization using optical image analysis. Miner Eng 21: 568-577

Larrea ML, Castro SM, BJerg EA (2014) A software solution for point counting. Petrographic thin section analysis as a case study. Arabian J Geosci 7: 2981-2989

LASTRA R (2007) Seven practical application cases of liberation analysis. Int J Miner Process 84: 337-347

LASTRA R, PAKTUNC D (2016) An estimation of the variability in automated quantitative mineralogy measurements through inter-laboratory testing. Miner Eng 95: 138-145

Le Bas MJ, Streckeisen AL (1991) The IUGS systematics of igneous rocks. J Geol Soc, London 148: 825-833

Le Maitre RW (2002) Igneous Rocks: A Classification and Glossary of Terms. Cambridge University Press, Cambridge, pp 1-236

LLOYD GE (1987) Atomic number and crystallographic contrast images with the SEM: a review of backscattered electron techniques. Mineral Mag 51: 3-19

London D (2008) Pegmatites. Canad Mineral, Spec Publ 10: pp 1-347

LotTer NO, Kormos LJ, Oliveira J, Fragomeni D, WhiteMAN E (2011) Modern process mineralogy: two case studies. Miner Eng 24: 638-650

Mineralogical Database (2017) Mineralogical database. Accessed on May 10, 2017 at http://www.webmineral.com

MotL D, FILIP V (2013) Method and apparatus for material analysis by a focused electron beam using characteristic X-rays and back-scattered electrons. (Patent no. WO2017050303 A1)

Müller A, Breiter K, Seltmann R, Pécskay Z (2005) Quartz and feldspar zoning in the eastern Erzgebirge volcano-plutonic complex (Germany, Czech Republic): evidence of multiple magma mixing. Lithos 80: 201-227 
Neumannová K, Thér R, Květina P, Hrstka T (2016) Perception of technological variability on the example of Neolithic settlement site in Bylany. Praehistorica 33: 291-306 (in Czech)

NIE J, PeNG W (2014) Automated SEM-EDS heavy mineral analysis reveals no provenance shift between glacial loess and interglacial paleosol on the Chinese Loess Plateau. Aeolian Res 13: 71-75

Pérez-Barnuevo L, Pirard E, Castroviejo R (2013) Automated characterisation of intergrowth textures in mineral particles. A case study. Miner Eng 52: 136-142

PIRARD E (2004) Multispectral imaging of ore minerals in optical microscopy. Mineral Mag 68: 323-333

PIRRIE D, Rollinson GK (2011) Unlocking the applications of automated mineral analysis. Geol Today 27: 226-235

Poliakov A, Donskoi E (2014) Automated relief-based discrimination of non-opaque minerals in optical image analysis. Miner Eng 55: 111-124

PoOler R, Dold B (2017) Optimization and quality control of automated quantitative mineralogy analysis for acid rock drainage prediction. Minerals 7: DOI 10.3390/ $\min 7010012$

ROLLinson GK, ANDERSEN JCØ, Stickland RJ, Boni M, FAIRHURST R (2011) Characterisation of non-sulphide zinc deposits using QEMSCAN ${ }^{\circledR}$. Miner Eng 24: 778-787

SANDMANN D, GUTZMER J (2013) Use of mineral liberation analysis (MLA) in the characterization of lithium-bearing micas. J Miner Mater Charact Eng 1: 285-292

SANDMANN D, GUTZMER J (2015) Nature and distribution of PGE mineralization in gabbroic rocks of the Lusatian Block, Saxony, Germany. Z Geol Wiss 166: 35-53

Sánchez E, Deluigi MT, Castellano G (2012) Mean atomic number quantitative assessment in backscattered electron imaging. Microsc Microanal 18: 1355-1361

Santoro L, Boni M, Rollinson GK, Mondillo N, BalasSONE G, CLEGG AM (2014) Mineralogical characterization of the Hakkari nonsulfide $\mathrm{Zn}(\mathrm{Pb})$ deposit (Turkey): the benefits of QEMSCAN ${ }^{\circledR}$. Miner Eng 69: 29-39

Santoro L, Rollinson GK, Boni M, Mondillo N (2015) Automated Scanning Electron Microscopy QEMSCAN ${ }^{\circledR}$ based mineral identification and quantification of the Jabali $\mathrm{Zn}-\mathrm{Pb}-\mathrm{Ag}$ nonsulphide deposit (Yemen). Econ Geol 110: 1083-1099
Slavík L, Valenzuela-Ríos Ji, Hladil J, Chadimová L, Liao JC, HušKová A, Calvo H, HrstKa T (2016) Warming or cooling in the Pragian? Sedimentary record and petrophysical logs across the Lochkovian-Pragian boundary in the Spanish Central Pyrenees. Palaeogeogr Palaeoclimatol Palaeoecol 449: 300-320

Smith DGW, Nickel EH (2008) Codification of unnamed minerals. J Petrol 49: 581-583

Smythe DM, Lombard A, Coetzee LL (2013) Rare Earth Element deportment studies utilising QEMSCAN technology. Miner Eng 52: 52-61

StONE M (1969) Nature and origin of banding in the granitic sheets Tremearne, Porthleven, Cornwall. Geol Mag 106: 142-158

SvojtKa M, Ackerman L, Medaris LG, Hegner E, Valley JW, Hirajima T, JeLÍNEK E, HrstKa T (2016) Petrologi$\mathrm{cal}$, geochemical and $\mathrm{Sr}-\mathrm{Nd}-\mathrm{O}$ isotopic constraints on the origin of garnet and spinel pyroxenites from the Moldanubian Zone of the Bohemian Massif. J Petrol 57: 897-920

ŠTEMPROK M (2016) Drill hole CS-1 penetrating the Cínovec/Zinnwald granite cupola (Czech Republic): an A-type granite with important hydrothermal mineralization. J Geosci 61: 395-423

ŠTEMPROK M, ŠULCEK Z (1969) Geochemical profile through an ore-bearing lithium granite. Econ Geol 64: 392-404

WARD I, Merigot K, MCInNES BIA (2018) Application of Quantitative Mineralogical Analysis in archaeological micromorphology: a case study from Barrow Is., Western Australia. J Archaeol Method Theory 25: 45-68

WhitNey JA, Stormer JC (1977) The distribution of NaAl$\mathrm{Si}_{3} \mathrm{O}_{8}$ between coexisting microcline and plagioclase and its effect on geothermometric calculations. Amer Miner 62: 687-691

WhitNey DL, Evans BW (2010) Abbreviations for names of rock-forming minerals. Amer Miner 95: 185-187

Žák K, Skála R, Řanda Z, Mizera J, Heissig K, AcKerman L, Duurišová J, Jonášová Š, Kameník J, Magna $\mathrm{T}$ (2016) Chemistry of Tertiary sediments in the surroundings of the Ries impact structure and moldavite formation revisited. Geochim Cosmochim Acta 179: $287-311$ 